\title{
The benefits and challenges of a continuous improvement area in a manufacturing plant
}

\author{
Benefícios e desafios da área de melhoria contínua em uma unidade de manufatura
}

\author{
Carlos Vinícius Vasconcellos de Magalhães Castro ${ }^{1 *}$; João Batista de Camargo Junior²®
}

Received: nov. 13, 2017

Accepted: aug. 07,2019

${ }^{1 *}$ Novelis Inc. - Continuous Improvement Specialist - 302 Mayde Rd - Madison County - 40403 - Berea, Kentucky, United States of America <carlos.vmc@gmail.com>

${ }^{2}$ UNIMEP - PhD in Administration - Rod. do Açúcar, Km 156 - Taquaral -13423-170 - Piracicaba, SP, Brazil

Creative Commons License. All the contents of this journal, except where otherwise noted, is licensed under a Creative Commons Attribution License.

\begin{abstract}
A continuous improvement area is a department of a company that seeks to support the implementation and execution of tasks focused on the improvement of processes, which can add additional value to production lines. As such, the goal of this paper was to identify the benefits of a continuous improvement area to plant production and the main challenges a rolled aluminum plant faces when implementing this program at all levels of manufacturing. The methodology used to achieve this goal was composed of qualitative interviews with 24 professionals from the company under analysis-including mechanical technicians, electrical technicians, and area leaders from the first, second, and third tiers of the company-and a comparison of our data analysis with that of the literature. The main results of this paper indicated that the benefits of the plant's continuous improvement area on production included the reduction of waste, the training of the workforce, and the translation of corporate goals into tangible goals for the plant. Meanwhile, we found the main challenges faced by the continuous improvement area during the application of this program to be an unwillingness of employees to change the way they perform their jobs and the identification of the best way to communicate with those involved in the program.
\end{abstract}

Keywords: Goal Deployment; Lean; Rolled aluminum; Six Sigma; Waste reduction.

\begin{abstract}
Resumo: A área de Melhoria Contínua é uma parte da empresa que busca suportar a implementação e execução de tarefas voltadas às melhorias dos processos, o que pode vir a gerar maior valor agregado nas linhas produtivas. Nesse contexto, $\mathrm{o}$ objetivo desse trabalho foi identificar os benefícios que a área de Melhoria Contínua fornece à produção da planta, bem como os principais desafios que enfrenta durante a aplicação do seu programa em todos os níveis de uma unidade de fabricação de bobinas de alumínio. A metodologia utilizada para atingir essa meta foi composta por entrevistas qualitativas com 24 profissionais da empresa estudada, incluindo líderes de área, técnicos mecânicos, técnicos elétricos e líderes de primeira, segunda e terceira camadas, e da análise dos dados a partir do confronto com a literatura. Os principais resultados do trabalho indicaram que os benefícios que a área de Melhoria Contínua fornece à produção da planta são compostos pela redução dos desperdícios, capacitação da força de trabalho e pelo desdobramento dos objetivos corporativos em objetivos tangíveis para a planta. Quanto aos principais desafios que enfrentaram durante a aplicação de seus programas, eles se relacionaram com pessoas que não estão dispostas a mudar a forma que executam seus trabalhos e em encontrar a melhor forma de se comunicar com os envolvidos no programa.
\end{abstract}

Palavras-chave: Implantação de metas; Lean; Bobinas de alumínio; Seis Sigma; Redução de desperdícios. 


\section{Introduction}

The primary goal of continuous improvement $(\mathrm{Cl})$ areas in most companies is to support implementing and executing tasks related to waste reduction, resulting in greater value added to production lines and processes (Duintjer, 2010; Ghinato, 2000).

The implementation of continuous improvement is normally driven by the Lean Six Sigma methodology, the resulting combination of Lean Management and Six Sigma methodologies. Lean Management originated from lean manufacturing, a term that was first used in a 1991 book from the Massachusetts Institute of Technology (MIT) to compare the recovery of U.S. and Japanese companies. At that time, Japanese automaker Toyota was the only company found to adhere to the lean manufacturing principles from MIT, although inside Toyota, these production behaviors were known as the Toyota Production System instead of as lean manufacturing. Lean manufacturing is therefore considered the successor of the Toyota Production System. Ten years following the first use of the term lean manufacturing in 1991, a new publication established the five principles of lean philosophy: i) define what value means to the customer; ii) clearly identify the product value stream; iii) optimize value stream flows to make them quick and robust; iv) develop products based on customer demand; and v) focus on excellence (Dekier, 2012).

The focus of lean manufacturing is the production line and waste reduction. Lean manufacturing does not have a clear focus on the human factors connected to manufacturing nor the management of those interactions. Thus, Lean Management targets resource management (and consequently waste reduction) not only of the production line, but also of the people involved in the processes. The fundamentals of Lean Management are: i) a strong workplace environment; ii) a clear definition of goals; iii) efficient and sufficient communication; iv) adequate motivation; v) utilization of human potential; vi) employee training; and vii) leadership capable of resolving conflict (Dekier, 2012).

In addition to the Lean Management principles, philosophy, and tools, Six Sigma is another methodology used in the area of $\mathrm{Cl}$. Six Sigma was developed at Motorola but became very popular through its implementation by General Electric in the mid-90s. This methodology uses statistical tools to understand and reduce the number of defects produced within manufacturing processes. The method of Six Sigma is that of DMAIC, an acronym for: define, measure, analyze, improve, and control. During each of these phases, a set of steps and tools must be followed to achieve the expected result. An additional aspect of Six Sigma is that it requires specific training to train those using the method-known as belts-to implement its steps and tools. These individuals receive training in the methodology and are responsible for using data-driven processes to make decisions and improve manufacturing processes (Pepper and Spedding, 2009).

Despite all the tools and techniques, the benefits presented by the area of $\mathrm{Cl}$ are often misinterpreted or badly structured, causing mistrust regarding such financial or structural improvements. This generates dissatisfaction among management and discourages the team implementing the task. Moreover, the benefits of a $\mathrm{Cl}$ area are often hard to measure, which further amplify its results as being abstract (Capell, 2004; Jones, 2013; Zimwara et al., 2013).

In addition to mistrusting $\mathrm{Cl}$ results, the area faces further challenges when implementing a new program or idea, often because of the way that the changes are presented to the final users, who in most cases are the shop floor operators. Therefore, $\mathrm{Cl}$ team members must overcome the obstacle of how final users perceive the $\mathrm{Cl}$ culture when shop floor operators become part of $\mathrm{Cl}$ activities by seeking alignment with leadership and ensure that the application of $\mathrm{Cl}$ values reach employees on the shop floor (Duintjer, 2010).

In this context, this article aims to identify the benefits that $\mathrm{Cl}$ areas provide to plant production and address the challenges faced during the application of a $\mathrm{Cl}$ program at all levels of manufacturing plant for rolled aluminum.

\section{Material and Methods}

\section{Study location}

This study was conducted in a manufacturing plant of an aluminum recycling company responsible for the production of aluminum ingots, the first step in a series of processes that result in a flat-rolled 
aluminum coil. The plant has been in existence for nearly 30 years and has approximately 140 employees. It is located in the state of Kentucky, in the U.S., and is responsible for the production of roughly 710 million pounds of aluminum ingots per year. The ingots are then shipped to the plant's only customer, another plant from the same company, and rolled into a sheet that is then sold to plants that manufacture aluminum cans.

\section{Study methodology}

To develop this research, we conducted a qualitative study by interviewing 24 employees from the company. The interviewees were from different departments and hierarchies. We aimed to obtain results that were as clear and encompassing as possible by comparing perspectives from leadership with those from shop floor operators and maintenance personnel. The latter groups represent the final customers from the $\mathrm{Cl}$ area, since leaders seek process improvements and cost reductions while shop floor personnel must implement such process changes on a daily basis.

The group interviewed consisted of: 12 area leaders (four shifts and three areas - Cold Metal, Hot Metal, and Direct Chill); two mechanical technicians (two shifts); two electrical technicians (two shifts); four firsttier leaders (from Business and Maintenance); three second-tier leaders (from Engineering, Maintenance, Reliability, and Automation; Quality and Continuous Improvement/Process; and Operations); and one thirdtier leader (plant manager).

This group of interviewees represents the areas most affected by $\mathrm{Cl}$ activities, either working within the defined path $\mathrm{Cl}$ must follow or working in a position affected by the changes implemented. The average tenure of those interviewed is roughly 20 years of service, and in a 28-year-old plant, this group is therefore a very experienced and knowledgeable representation of the plant. Other areas that interact with this group of interviewees are also part of the $\mathrm{Cl}$ culture and participate in events and training and perform improvements for the area. However, the focus of this study is to understand the effects of $\mathrm{Cl}$ on production, specifically.

\section{Chosen Material}

We collected data for this study by a process of open interviews, where all interviewed employees were asked questions regarding the benefits of and challenges faced by $\mathrm{Cl}$. All interviews included introductory questions regarding interviewees' names, job titles, time working for the company, area, whether or not they were from leadership, and whether or not they had already worked in $\mathrm{Cl}$. Following these initial questions, the interview proceeded with questions regarding the existing $\mathrm{Cl}$ program, its benefits, factors impacting its implementation, whether or not certain groups within the company were unwilling to accept the $\mathrm{Cl}$ culture, whether or not they were able to apply the $\mathrm{Cl}$ concepts to their daily tasks, and whether the area of $\mathrm{Cl}$ helped with understanding the needs of the business. We used these more detailed questions to obtain insight into how the $\mathrm{Cl}$ culture affected plant personnel and how plant personal engaged in $\mathrm{Cl}$ culture. Moreover, such questions provided insight into the presence of any detractors within the company that could render the implementation and stability of $\mathrm{Cl}$ culture more difficult. In addition, the interviews provided an understanding of the way in which $\mathrm{Cl}$ could assist plant personnel with their daily tasks. We then analyzed interview responses and compared them to findings from the literature to make inferences and conclusions regarding the challenges and benefits faced by the $\mathrm{Cl}$ area.

\section{Results and Discussion}

In this chapter, we first present results from the interviews and then a comparison of interviewee responses with the literature. The interview involved six questions and the first focused on the benefits that a $\mathrm{Cl}$ area provides the company. Overall, the interviewees viewed $\mathrm{Cl}$ as having the potential to streamline processes by focusing on waste reduction, encouraging problem-solving, and training employees on $\mathrm{Cl}$ methodology. One leader in Cold Metal mentioned that the $\mathrm{Cl}$ area also helps the company reach its financial goals.

Next, the interviewees were asked to explain the factors most critical in the implementation of $\mathrm{Cl}$. Ninety percent of responses to this question stated that a demonstration of the benefits of $\mathrm{Cl}$ was most critical for its implementation. Certain employees within the leadership group noted that regarding the acceptance of $\mathrm{Cl}$ changes - the group responsible for implementing $\mathrm{Cl}$ must understand 
that such changes take time. On the operational level, data collected showed that one of the focus areas of $\mathrm{Cl}$ activities is to facilitate the life of the worker.

The next interview question regarded the engagement of people in the $\mathrm{Cl}$ program. While the operational level did not highlight any specific group of workers in their answers, they explained that the employees less inclined to accept $\mathrm{Cl}$ methodologies are those who prefer not to change the status quo. Overall, most interviewees conveyed a positive mindset of $\mathrm{Cl}$ acceptance among plant workers.

The interviewed were next asked about the ease of understanding $\mathrm{Cl}$ goals and the extent to which these goals were defined at the plant. All interviewees expressed that the $\mathrm{Cl}$ goals are well defined and understood, since the company has a committee in place that reviews these goals on a monthly basis. However, the responses of some interviewees were not as positive, as they expressed that communication surrounding $\mathrm{Cl}$ implementation could be improved. Management suggested that $\mathrm{Cl}$ goals should not only consider the $\mathrm{Cl}$ program, but extend to the entire plant and the business in general.

In the fifth question, the interviewees were asked about the use of $\mathrm{Cl}$ thinking for daily tasks. The respondents were nearly in consensus, with only one respondent from leadership claiming that they do not follow $\mathrm{Cl}$ thinking during their activities and that many daily activities suffered from operational inefficiencies. However, apart from this individual, all other respondents claimed to use the $\mathrm{Cl}$ mindset in their daily activities to improve their jobs and render them more productive. Respondents from Operations and Maintenance largely agreed with this last comment.

The last question of the interview sought to understand if $\mathrm{Cl}$ is responsible for providing an understanding of the needs of the customer and of leadership, and the responses showed that the different levels of the company were not in full agreement. Some responses were negative, claiming that communication among everyone involved in $\mathrm{Cl}$ goals could be better and noting that sometimes goals and changes were imposed without soliciting any feedback. Meanwhile, some interviewees were more positive, mentioning that they could rely on the $\mathrm{Cl}$ area to help achieve goals when necessary.

We now compare the findings from the interviews with those from the literature. According to the interviewee responses, most of the benefits observed were compatible with those described by Pepper and Spedding (2009), who highlight that $\mathrm{Cl}$ can play a role in reducing losses in daily production activities, in improving the capacity of labor by introducing tools and methodologies to help workers understand and improve certain process, and in improving the financial performance of the company. We note that this last benefit was also mentioned by an operator interviewed, who recognized that $\mathrm{Cl}$ results should ultimately focus on the financial side of the company. Indeed, the interview results lend insight into the actual benefits of $\mathrm{Cl}$ in a company. Meanwhile, research has shown that one of the critical pieces for the successful implementation of a $\mathrm{Cl}$ program is the involvement of those implementing the changes and their recognition of the value of thinking and acting according to $\mathrm{Cl}$ methods. This is, in fact, similar to what respondents observed; however, they did not mention another critical factor - the communication of $\mathrm{Cl}$ activities, results, and next steps to all those at the plant. This is likely due to the interviewees' belief that communication in the plant was sufficient to get everyone involved in the activities (Duintjer, 2010; Pepper and Spedding, 2009; Vanek et al., 2015).

With respect to those less inclined to accept $\mathrm{Cl}$ methods, Kotter and Schlesinger (2008) argued that people are resistant to change because of the following: they may not see the value in accepting a new way of performing their work; they may not trust the reason behind the change implemented by the company; or they feel that they will have to exert too much effort into making the changes and the results will not be worth this effort. The authors claim that people may also worry about not being able to deliver what is expected of them. The interviewee responses tended to confirm the argument that people are resistant to change. However, the interviewees did not mention a lack of trust either in the reason for the changes, in the value behind performing their work differently, or in the effort necessary to implement the changes and achieve the desired results. In addition, a particular group from Leadership observed that Maintenance was less likely to adhere to the $\mathrm{Cl}$ methods, confirming what is described by Duintjer (2010). The author found that due to the repetitive nature of the work to implement $\mathrm{Cl}$ methods, those with higher seniority generally believe that they have already mastered such methods and are already performing their jobs optimally. 
Regarding the definition and understanding of $\mathrm{Cl}$ goals, interestingly, interviewees were confident in claiming that they understood $\mathrm{Cl}$ goals. This differs from what was observed by Jones (2013), that $\mathrm{Cl}$ goals are commonly difficult to define and present in a way that those to be involved in $\mathrm{Cl}$ activities can comprehend. Furthermore, others have found a lack of confidence and doubt generated regarding $\mathrm{Cl}$ areas and their ability to deliver results (Capell, 2004; Kovacheva, 2010). However, the responses from interviewees reflected the acceptance of $\mathrm{Cl}$ methods, since an understanding of $\mathrm{Cl}$ goals can help those working on such activities identify when results conform to the established goals.

Lean Management and Six Sigma provide methodologies that are expected to be used by all those involved in a $\mathrm{Cl}$ program, and not only by those in the $\mathrm{Cl}$ area itself (Maleszka and Linke, 2016). Interviewee responses overall agreed in this respect, that those performing the work should be trained in $\mathrm{Cl}$ methods. When $\mathrm{Cl}$ knowledge is passed on to those performing the work, these individuals can seek improvements by reducing waste and focusing on solving problems they encounter - not only using temporary fixes, but by setting new standards, simplifying tasks, and ultimately making their work more efficient. Requests for improvement by those performing the work are common, as these individuals may not be certain as to the correct use of $\mathrm{Cl}$ tools during daily activities and may not have a complete framework defining how the tools are to be implemented. In addition, expectations regarding the effectiveness of $\mathrm{Cl}$ tools to improve routine processes can differ from one person to another (Espinoza, 2005; Miron et al., 2016; Pepper and Spedding, 2009).

A link between a company's business and operational needs, as defined by Terziovski (2002), a Cl area should aid in communicating goals related to each, and in translating $\mathrm{Cl}$ activities and improvements to the operational level. This definition was confirmed during our interviews and we found that $\mathrm{Cl}$ appears to deliver on contributing to improvements in daily plant activities while also aiding leadership in conveying $\mathrm{Cl}$ knowledge and developing a problem-solving mindset at the operational level of the company.

\section{Conclusions}

Our results lead us to conclude that overall, the plant has a strong knowledge regarding the elements of, benefits of, and the possible barriers to the $\mathrm{Cl}$ program and culture. The respondents not only understand the value of $\mathrm{Cl}$, but also view it as an area that assists in making plant processes more efficient by reducing waste. Additionally, we found that $\mathrm{Cl}$ maintains workers informed by the deployment of Lean Six Sigma methodologies and by translating business goals into more tangible goals for the plant. Regarding the challenges of $\mathrm{Cl}$ implementation, the plant personnel interviewed demonstrated that while certain people prefer not to change the way of performing their work, the presence of a $\mathrm{Cl}$ area furthers the awareness of $\mathrm{Cl}$ and aids in the implementation of $\mathrm{Cl}$ methodologies, since most individuals in the company are already part of the $\mathrm{Cl}$ program and using the related tools on a daily basis. Communication of $\mathrm{Cl}$ goals can further improve the $\mathrm{Cl}$ program in the company, to help the understanding of $\mathrm{Cl}$ by plant personnel and ultimately improve the sustainability of the business.

How to cite: Castro, C.V.V.M.; Camargo Junior, J.B. 2020. Benefits and challenges that the Continuous Improvement area faces in a manufacturing unit. Quaestum 1: e26750528

Author Contributions: Conceptualization: Castro C.V.V.M.; Camargo Jr, J.B. Data acquisition: Castro C.V.V.M. Data analysis: Castro C.V.V.M. Design of methodology: Castro C.V.V.M.; Camargo Jr, J.B. Writing and editing: Castro C.V.V.M.; Camargo Jr, J.B.

\section{Referências}

Capell, P. 2004. Benefits of Improvement Efforts. Special Report. Carnegie Mellon University, Pittsburgh, PA, U.S.A. Dekier, Ł. 2012. The Origins and Evolution of Lean Management System. Journal of International Studies 5(1): 46-51.

Duintjer, R. 2010. The implementation of continuous improvement and the resistance to change: 'A case study at the maintenance department in a large industrial organization'. Master thesis, Universiteit van Amsterdam, Amsterdam, $\mathrm{NH}$, Netherlands.

Espinoza, M. 2005. Strategy to maximize maintenance operation. Executive MBA, Faculty of Business Administration, Simon Fraser University, Burnaby, BC, Canada. Available in: <https://core.ac.uk/download/pdf/56372338.pdf> Access in: jun. $02,2017$.

Ghinato, P. 2000. Elementos Fundamentais do Sistema Toyota de Produção. p. 32-59. In: Almeida, A.T.; Souza, F.M.C. (Eds). Produção \& Competitividade: Aplicações e Inovações. Editora da UFPE, Recife, PE, Brazil. 
Jones, B. 2013. Identifying Real Cost Saving in Lean Manufacturing. Purdue e-Pubs. Aviation Technology Graduate Student Publications, Purdue University, West Lafayette, IN, U.S.A. Available in: <https://docs.lib.purdue.edu/cgi/ viewcontent.cgi?article=1027 \& context=atgrads $>$. Access in: jun. 02, 2017.

Kotter, J.P.; Schlesinger, L.A. 2008. Choosing Strategies for Change. Harvard Business Review 86: 130-139.

Kovacheva, A.V. 2010. Challenges in Lean implementation - Successful transformation towards Lean enterprise. Master thesis. Available in: <https://www.semanticscholar.org/paper/Challenges-in-Lean-implementation-Successful-LeanKovacheva-Araujo/b2f1ed95cd3b328a963d9ab3f3ebb9e688287062>. Access in: may 25, 2017.

Maleszka, A.; Linke, M. 2016. Improvement of Management Process by Using Lean Six Sigma Tools in Some Big Organization of Food Industry. Polish Journal of Natural Sciences 31(1): 101-112.

Miron, L.; Talebi, S.; Koskela, L.; Tezel, A. 2016. Evaluation of Continuous Improvement Programmes. Proceedings 24th Annual Conference of the International. Group for Lean Construction: 23-326. Available in: <http://www.iglc.net/>. Access in: jun 19, 2017.

Pepper, M.P.J.; Spedding, T.A. 2009. The evolution of Lean Six Sigma. International. Journal of Quality \& Reliability Management 27(2): 138-155.

Terziovski, M. 2002. The Effects of Continuous Improvement and innovation management practice on small to medium enterprise (SME) performance. Special Report, The University of Melbourne, Parkville, VIC, Australia.

Vanek, M.; Spakovska, K.; Mikolas, M.; Pomothy, L. 2015. Continuous Improvement Management for Mining Companies. The Journal of The Southern African Institute of Mining and Metallurgy 115: 119-124.

Zimwara, D.; Mugwagwa L.; Maringa D.; Mnkandla A.; Mugwagwa L.; Ngwarati, T.T. 2013. Cost of Quality as a Driver for Continuous Improvement - Case Study - Company X. International Journal of Innovative Technology and Exploring Engineering 2(2): 132-139. 